\title{
Closed suction drainage with or without re-transfusion of filtered shed blood does not offer advantages in primary non-cemented total hip replacement using a direct anterior approach.
}

\author{
Kleinert, K ; Werner, C M L ; Mamisch-Saupe, N ; Kalberer, F ; Dora, C
}

\begin{abstract}
The possibility to re-transfuse drained blood was not an argument for using drains and, accepting more thigh swelling, we stop to use drains in simple non-cemented primary THR using the direct anterior approach.
\end{abstract}

DOI: https://doi.org/10.1007/s00402-011-1387-1

Posted at the Zurich Open Repository and Archive, University of Zurich ZORA URL: https://doi.org/10.5167/uzh-55952

Journal Article

Published Version

Originally published at:

Kleinert, K; Werner, C M L; Mamisch-Saupe, N; Kalberer, F; Dora, C (2012). Closed suction drainage with or without re-transfusion of filtered shed blood does not offer advantages in primary non-cemented total hip replacement using a direct anterior approach. Archives of Orthopaedic and Trauma Surgery, 132(1):131-136.

DOI: https://doi.org/10.1007/s00402-011-1387-1 


\title{
Closed suction drainage with or without re-transfusion of filtered shed blood does not offer advantages in primary non-cemented total hip replacement using a direct anterior approach
}

\author{
Kathrin Kleinert • Clément Werner • \\ Nadja Mamisch-Saupe $\cdot$ Fabian Kalberer • \\ Claudio Dora
}

Received: 26 April 2011/Published online: 28 August 2011

(C) Springer-Verlag 2011

\begin{abstract}
Introduction Wondering if the use of drains allowing retransfusion of shed blood as opposed to closed suction drains or no drains would improve quality of care to patients undergoing simple non-cemented primary total hip replacement (THR) using a direct anterior approach, a three-arm prospective randomized study was conducted.

Method One hundred and twenty patients were prospectively randomized to receive no drain, closed suction drains or drains designed for re-transfusion of shed blood. Blood loss, VAS pain scores, thigh swelling, hematoma formation, number of dressings changed and hospital stay were compared and patients followed for 3 months.

Results Drains did not have any significance on postoperative haemoglobin and haematocrit levels or homologous blood transfusion rates. Patients receiving homologous blood transfusions had too small drain volumes to benefit from re-transfusion and patients, who get drained fluid re-transfused, were far away from being in need of
\end{abstract}

\footnotetext{
K. Kleinert · C. Dora $(\bowtie)$

Department of Orthopaedics, University of Zurich,

Balgrist Hospital, Forchstrasse 340, 8008 Zürich, Switzerland

e-mail: claudio.dora@balgrist.ch

C. Werner

Department of Traumatology, University of Zurich,

Rämistrasse 100, 8091 Zürich, Switzerland

N. Mamisch-Saupe

Department of Radiology, University of Zürich,

Balgrist Hospital, Forchstrasse 340, 8008 Zürich, Switzerland

F. Kalberer

Department of Orthopaedics, Kantonsspital Winterthur,

Brauerstrasse 15, 8401 Winterthur, Switzerland
}

homologous blood transfusion. Omitting drains resulted in more thigh swelling accompanied with a tendency of slightly more pain during the first postoperative day but without effect on clinical and radiological outcome at 3 months. Earlier dry operation sites resulting in simplified wound care and shorter hospital stay was encountered when no drain was used.

Conclusion The possibility to re-transfuse drained blood was not an argument for using drains and, accepting more thigh swelling, we stop to use drains in simple noncemented primary THR using the direct anterior approach.

Keywords Drainage $\cdot$ Suction $\cdot$ Re-transfusion $\cdot$ Blood loss · Total hip replacement - Direct anterior approach . Minimally invasive

\section{Introduction}

The use of closed suction drains in aseptic orthopaedic surgery and primary total hip replacement (THR) remains controversial. Increased infection rates due to non-drained hematoma providing excellent culture medium $[1,2]$ or drains acting as a conduit into the depth of the wound [3-5] as well as persistent oozing from the surgical incision or out of the drainage hole $[1,6]$ are potential disadvantages of both, using or omitting drains. Additionally, using drains might increase needs for homologous blood transfusions or reduce them by postoperative re-transfusion of drained blood [7-12].

Due to the low incidence of septic complications, sample sizes needed to elucidate the impact of drains on infection rate cannot be the scope of a single centre study. Additionally, considering the different surgical approaches (minimally invasive vs. conventional, posterior, lateral, 
anterior) and implant fixations (cemented, hybrid, noncemented) used in primary THR, having most probably impacts on the amount of bleeding after wound closure, it can neither be the scope of an investigation to elucidate if, and what kind of drains generally should be used.

Nevertheless, in order to optimize quality of care to patients undergoing primary THR using the same approach and the same non-cemented implants, it would be valuable to know if it is worthwhile to omit or use drains with or without the possibility to retransfuse drained blood. Our hypothesis was that, in terms of postoperative wound care, early postoperative pain levels, follow-up haemoglobin levels and frequency of homologous blood transfusions omission of closed wound drainages would not be inferior than using simple closed suction drains or drains allowing re-transfusion of drained blood. This knowledge could also be of interest for other surgeons using similar implants and surgical techniques. Therefore, a prospective randomized three arm study was conducted to answer this question.

\section{Materials and methods}

Institutional ethical review board approved this study designed to prospectively compare three groups of patients undergoing primary THR with three different protocols for wound drainage.

Between October 2008 and Mai 2009, a consecutive series of 181 patients undergoing THR for simple osteoarthritis were enrolled. Excluded were patients denying signed informed consent, with history of coagulation disorders, having received medicine affecting the coagulation system up to 10 days before surgery, having preoperative anaemia (haematocrit value $<35 \%$ for men, $<30 \%$ for women) or suffering from avascular necrosis of the femoral head, as this might be associated with increased bleeding [13].

The day before surgery thigh circumference was measured $15 \mathrm{~cm}$ distal to the anterior superior iliac spine (ASIS). Preoperative haemoglobin (Hb) level and haematocrit (Hct) was part of the routine preoperative assessment. Two orthopaedic surgeons performed all surgeries in spinal or general anaesthesia according to the preference of the patient and the anaesthetist. All patients were given preoperative enoxaparin natrium $40 \mathrm{mg}$ the evening before surgery and on a daily dose for 6 weeks. Three doses of cefuroxime $1.5 \mathrm{~g}$ were given in an $8 \mathrm{~h}$ interval starting $30 \mathrm{~min}$ before incision. A direct anterior approach in the supine position on an extension-distraction table (AMIS mobile leg positioner, Medacta, Castel San Pietro, Switzerland) was used. The skin incision was centred on the top of the tensor fascia latae muscle (TFL) and its fascial sheath entered before blunt dissection along its medial border was performed. After ligation of the ascending branch of the lateral circumflex femoral artery a U-shaped capsulotomy was made to protect TFL followed by the anchoring of a soft-tissue retractor within the joint capsule. After implantation of the acetabular component the leg was secured in about $20^{\circ}-30^{\circ}$ of extension, $90^{\circ}$ of external rotation and $20^{\circ}$ of adduction using the leg positioner for preparation of the femoral canal. The same noncemented implants (Quadra ${ }^{\circledR}-\mathrm{H}$ stem, Versafit ${ }^{\circledR}-\mathrm{CC}$ cup, highly cross linked polyethylene inlay and 28 chromecobalt head, Medacta, Castel San Pietro, Switzerland) were used in all patients. Blood vessels were coagulated throughout the procedure. Patients were then block randomized to one of three groups from sealed envelopes opened by the anaesthetist at the end of surgery just before fascial closure. Group A received no drain, Group B a closed suction $3.5 \mathrm{~mm}$ drain (CSD) connected to a vacuumed ( -900 mbar) drainage bottle (Redon ${ }^{\circledR}, \mathrm{B} /$ Braun) and Group $\mathrm{C}$ an ABTrans autologous retransfusion system (Bellovac-ABT ${ }^{\circledR}$, Astratec). The latter includes two drains with a Y-connector and a $125 \mu \mathrm{m}$ filter through which the blood passes before entering the 1,200 $\mathrm{ml}$ reservoir. Drains were lying on the capsule, deep to the tensor fasciae latae muscle. The wound was closed in layers with a continuous Everett suture (Maxon Loop ${ }^{\circledR}$, Tyco) for the fascia lata, a continuous monofil suture (Maxon ${ }^{\circledR} 3.0$, Tyco) for the subcutaneous layer, single cuticular stitches (Maxon ${ }^{\circledR} 4,0$, Tyco) and a continuous intracutaneous suture (Maxon ${ }^{\circledR}$ 4,0 , Tyco). Patients started walking with weight bearing as tolerated at day 1 . Autologous re-transfusion was given when more than $250 \mathrm{ml}$ was collected within $6 \mathrm{~h}$. Both drainage systems were removed after $48 \mathrm{~h}$. Homologous blood transfusions were given if the postoperative $\mathrm{Hb}$ was less $80 \mathrm{~g} / \mathrm{l}$ or if patients were symptomatic with $\mathrm{Hb}$ values in the range $80-100 \mathrm{~g} / \mathrm{l}$ according to in house guidelines. Patients were considered symptomatic if they complained from breathlessness, heart palpitations, dizziness or headache and if weakness impaired them from starting walking during the first 2 days.

The total number of transfusions was recorded. Operating time and intraoperative blood loss was recorded by the anaesthetists on their protocol. Total blood loss was estimated from $\mathrm{Hb}$ concentrations and Hct values recorded preoperatively and on the third postoperative day. During the postoperative phase, pain was evaluated daily until day 3 using a Visual Analog Scale (0 [none]-10 [strong pain]). Swelling of the thigh was recorded on the second postoperative day after drain removal by measuring thigh circumference $15 \mathrm{~cm}$ distal to ASIS and comparing it to preoperative. Hematoma formation was additionally measured by a radiologist using ultrasound (volume $\left(\mathrm{cm}^{3}\right)$ : width $(\mathrm{cm}) \times$ depth $(\mathrm{cm}) \times$ cranio-caudal expansion $(\mathrm{cm}) \times 314] / 6)$ at day 2 . A hydrocolloid wound draping 
$\left(\right.$ Comfeel $^{\circledR}$, Coloplast $\mathrm{AG}$ ) aimed to be removed only 14 days after surgery was used. Due to its specific features, this draping avoids maceration of the wound and prevents contamination due to dressing changes or contact with water. It was changed only if leakage was present. In this case, a conventional dressing was applied. Conventional dressings of the surgical incision as well as of the drain hole were changed as soon as they were soaked and counted. A dry surgical incision and drain hole was a prerequisite for hospital discharge. Hospital stay was recorded in days. All patients were postoperatively monitored for postoperative pyrexia, transfusion reactions, wound or other complications. The patients attended for follow-up at 6 weeks for a blood check ( $\mathrm{Hb}, \mathrm{Hct}$, leukocyte count, CRP) and at 3 months for clinical examination according to the Harris Hip Score (HHS) and anteroposterior and cross table lateral X-rays. Presence of heterotopic ossification was graded according to Brooker et al. [14].

Sample Size calculation including Bonferroni-Dunn correction resulted in a minimum of 40 patients required in each group in order to detect a difference between preand postoperative haemoglobin values of one standard deviation $(1.3 \mathrm{~g} / \mathrm{dl})$ ( $80 \%$ power, $\alpha$ value of 0.017$)$. Intention to treat analysis was chosen for the case that a drain would inadvertently be removed earlier. One-way ANOVA and Kruskal-Wallis tests were used to analyze continuous data and the Fisher exact test for categorical data.

\section{Results}

From 181 patients enrolled 61 were excluded because of denied informed consent (21), history of coagulation disorders (5), medications affecting the coagulation system up to 10 days before surgery (21), preoperative anaemia (5) and avascular necrosis of the femoral head (9). They all were treated using a closed suction drain. The remaining 120 patients were included. In terms of age, gender, side, body mass index and preoperative HHS the three groups of patients did not differ significantly from each other (Table 1). Mean surgical time averaged $115 \pm 26$ (60-180) $\mathrm{min}$ and was not significantly different between the groups $(p=0.55)$. Intraoperative blood loss averaged $408 \pm 231(50-1,500) \mathrm{ml}$ and showed no significant differences between the three groups $(p=0.57)$. In one patient of group $\mathrm{B}$ and $\mathrm{C}$ each, the drain inadvertently was removed during application of the postoperative dressing. Both patients remained in their respective groups.

Preoperative and later $\mathrm{Hb}$ and $\mathrm{Hkt}$ values are summarized in Table 2 and did not significantly differ between the groups.

Numbers concerning pain, thigh swelling, hematoma volume, hospital stay and homologous blood transfusions are summarized in Table 3. Patients without postoperative drain had slightly higher pain scores during the first day but this difference did not reach significance level $(p=0.31)$. Thigh swelling was significantly more pronounced in patients without drains $(p=0.013)$ and hematoma volume

Table 1 Patient's demographics

\begin{tabular}{lllll}
\hline & Group A $(n=40)$ & Group B $(n=40)$ & Group C $(n=40)$ & $p$ \\
\hline Mean age \pm SD (range) in years & $66 \pm 10(47-91)$ & $64 \pm 11(46-84)$ & $66 \pm 10(45-84)$ & $19 / 21$ \\
Gender: female/male & $23 / 17$ & $19 / 21$ & $24 / 16$ & $0.782^{\boldsymbol{\varepsilon}}$ \\
Side: right/left & $23 / 17$ & $24 / 16$ & $28 \pm 5(20-39)$ \\
Mean BMI \pm SD (range) & $26 \pm 10(15-38)$ & $26 \pm 5(17-38)$ & $0.179^{\mathfrak{\varepsilon}}$ \\
Mean HHS \pm SD (range) & $52 \pm 14(13-79)$ & $54 \pm 12(27-79)$ & $55 \pm 15(20-79)$ & $0.812^{\boldsymbol{k}}$ \\
\hline
\end{tabular}

\& One-way ANOVA

${ }^{£}$ Fisher exact test comparing group A and B

Table $2 \mathrm{Hb}$ values in $\mathrm{g} / \mathrm{l}$ and $\mathrm{Hkt}$ values in proportion of 1

\begin{tabular}{|c|c|c|c|c|}
\hline & Group A $(n=40)$ & Group B $(n=40)$ & Group C $(n=40)$ & $p^{\&}$ \\
\hline Mean $\mathrm{Hb}$ preop. (range) & $136(97-163)$ & $140(102-166)$ & $142(114-171)$ & 0.666 \\
\hline Mean $\mathrm{Hb}$ postop. (range) & $99(66-123)$ & $102(72-132)$ & $106(79-144)$ & 0.685 \\
\hline Mean Hb f-up (range) & $129(98-152)$ & $131(104-156)$ & $130(103-158)$ & 0.776 \\
\hline Mean Hkt preop. (range) & $0.41(0.31-0.51)$ & $0.41(0.34-0.47)$ & $0.42(0.35-0.49)$ & 0.812 \\
\hline Mean Hkt postop. (range) & $0.29(0.19-0.37)$ & $0.3(0.22-0.38)$ & $0.31(0.22-0.41)$ & 0.785 \\
\hline Mean Hkt f-up (range) & $0.39(0.27-0.45)$ & $0.39(0.28-0.46)$ & $0.38(0.27-0.47)$ & 0.873 \\
\hline
\end{tabular}

\& One-way ANOVA 
Table 3 Variables during hospital stay

\begin{tabular}{|c|c|c|c|c|}
\hline & Group A $(n=40)$ & Group B $(n=40)$ & Group C $(n=40)$ & $p$ \\
\hline Mean pain VAS day $1 \pm$ SD (range) & $2.1 \pm 1.7(0-7)$ & $1.4 \pm 1.9(0-8)$ & $1.2 \pm 1.5(0-7)$ & $0.499^{\$}$ \\
\hline Mean pain VAS day $2 \pm$ SD (range) & $1.4 \pm 2.3(0-10)$ & $1 \pm 1.5(0-5)$ & $0.7 \pm 1.2(0-6)$ & $0.336^{\$}$ \\
\hline Mean pain VAS day $3 \pm$ SD (range) & $0.7 \pm 1.2(0-6)$ & $0.7 \pm 1.2(0-5)$ & $0.7 \pm 1.2(0-6)$ & $0.87^{\$}$ \\
\hline Mean Thigh swelling \pm SD (range) in $\mathrm{cm}$ & $5.3 \pm 2.5(1-10)$ & $3.8 \pm 2.3(0-9)$ & $4.2 \pm 2.3(0-9)$ & $0.013^{\&}$ \\
\hline Mean hematoma $\pm \mathrm{SD}$ (range) in $\mathrm{cm}^{3}$ & $5.3 \pm 14.8(0-72)$ & $3.8 \pm 2.3(0-64)$ & $2 \pm 8.2 .0(0-50)$ & $0.143^{\&}$ \\
\hline Mean hospital stay \pm SD (range) in days & $5.4 \pm 1.0(4-7)$ & $6.6 \pm 1.0(5-9)$ & $6.7 \pm 1.4(5-9)$ & $0.001^{\&}$ \\
\hline Patients receiving homologous blood & 4 & 4 & 1 & 0.152 \\
\hline
\end{tabular}

\$ Kruskal-Wallis test

\& One-way ANOVA

${ }^{£}$ Fisher exact test comparing group B and C

as measured by ultrasound was higher in tendency but not significantly different when compared to the groups with drains $(p=0.143)$. Patients without drain earlier showed a dry surgical site (surgical incision and drain hole), got less number of dressing changes $(p=0.001)$ and were discharged from hospital 1 day earlier than patients with drains ( $p=0.001$ ). Homologous blood transfusion was given to 9 of 120 patients $(7.5 \%)$, four patients from group A and B each and one patient from group $\mathrm{C}$. The mean drain volume of the five patients from group $\mathrm{B}$ and $\mathrm{C}$ receiving homologous blood transfusion averaged 205 (140-240) $\mathrm{ml}$ and did not reach the re-transfusion level set at $250 \mathrm{ml}$. When compared to all other patients, patients receiving homologous blood transfusions had similar preoperative $\mathrm{Hb}$ values [128 g/l (112-148) vs. $139 \mathrm{~g} / \mathrm{l}(102-171), p=0.182]$ but significantly less postoperative Hb values $79 \mathrm{~g} / \mathrm{l}(66-89) \mathrm{vs}$. $103 \mathrm{~g} / \mathrm{l}(66-144),(p=0.042)$ (Table 4).

Only three patients $(7.5 \%)$ from group $\mathrm{C}$ benefited from shed blood re-transfusion. Their mean $\mathrm{Hb}$ value was 108

Table 4 Subgroup of re-transfused patients with homologous blood $(n=9)$

\begin{tabular}{lcll}
\hline & $\begin{array}{l}\text { Re-transfused } \\
\text { subgroup }(n=9)\end{array}$ & $\begin{array}{l}\text { Collective } \\
(n=111)\end{array}$ & $p^{\mathbf{k}}$ \\
\hline Pre-Hb & $128(112-148)$ & $139(102-171)$ & 0.182 \\
Post-Hb & $79(66-89)$ & $103(66-144)$ & 0.042 \\
$\begin{array}{l}\text { Intraoperative } \\
\text { blood loss }\end{array}$ & $428(200-800)$ & $409(50-1,500)$ & 0.434 \\
\hline
\end{tabular}

\& One-way ANOVA
(103-112) g/l and none had clinical symptoms of anaemia. The mean re-transfused volume was $267 \pm 29$ (250-300) $\mathrm{ml}$. In the other 37 patients, the drained volume within the first $6 \mathrm{~h}$ was less than $250 \mathrm{ml}$ and discarded. Overall the mean quantity of blood collected in the ABTrans autologous re-transfusion system was $127.2 \pm 63.8$ (10-300) ml.

One non-dislocated intraoperative trochanteric fracture occurred in each of group B and $\mathrm{C}$ and altered postoperative care in terms of changing to partial weight bearing for 6 weeks instead of weight bearing as tolerated. This complication did not result in autologous blood transfusion or hospital stay lengthening. Delayed wound healing was noticed in one each of group $\mathrm{B}$ and $\mathrm{C}$ and revised by superficial partial wound excision after 3 weeks. No infections were observed. One periprosthetic fracture occurred in each of group A and C after two days (stumbling and falling) and 4 weeks (fall down the stairs at home), respectively. Both needed surgical revision.

At 3 months 118 out of 120 patients could be evaluated. The mean HHS was 87 (60-99) and showed no differences between the groups $(p=0.753)$. Grade 1 heterotopic ossifications occurred in 4, 1 and 5 patients from group A, $\mathrm{B}$ and $\mathrm{C}$, respectively (Table 5). They did not have clinical relevance.

\section{Discussion}

The aim of the present study was to know if in terms of blood loss, frequency of homologous blood transfusions,

Table 53 months follow-up

\begin{tabular}{lllll}
\hline & Group A $(n=39)$ & Group B $(n=40)$ & Group C $(n=39)$ & $p$ \\
\hline HO & 4 & 1 & 5 & $0.087^{\mathfrak{k}}$ \\
Harris hip score & $88(65-99)$ & $88(60-98)$ & $82(60-98)$ & $0.753^{\boldsymbol{*}}$ \\
\hline
\end{tabular}

${ }^{£}$ Fisher exact test comparing group $\mathrm{B}$ and $\mathrm{C}$

\& One-way ANOVA 
pain, thigh swelling, hematoma formation, wound care and hospital stay, the use of drains allowing re-transfusion of shed blood as opposed to closed suction drains or no drains would improve quality of care to patients undergoing THR using a direct anterior approach and non-cemented implants.

To our knowledge, it is the first three-arm prospective study on this matter strictly confined, not only to THR, but also to a particular surgical technique and type of implant fixation. This is considered a strength of the present study, because advantages and disadvantage of drains might be very different (1) in total knee replacement, where the main bleeding is expected to occur after opening the tourniquets and wound closure $[9,12,15]$, (2) when using cemented implants, where opened bony surfaces are sealed by cement, and (3) when using different surgical approaches, where the extend of splitting muscle may also have an impact on bleeding. This confinement to a particular surgical technique and implant might also be considered a weakness, because the results are not uncritically transposable to other techniques of THR.

In terms of postoperative $\mathrm{Hb}$ values, omitting or using drains did not have any impact. This agrees with the majority of other reports on this topic $[6,16]$ and may corroborate that an effect of "sucking out" does not appear when using drains.

Homologous blood transfusion rate was $7.5 \%$ and lower than in other investigations [17, 18], especially those promoting the use of wound drainage systems featured by an autologous re-transfusion system [11]. One reason may be the surgical approach strictly following an inter-nervous and inter-muscular plane, thus eventually reducing bleedings when compared to more conventional approaches. However, we are not aware of investigations corroborating this eventuality. Interestingly, none of the five patients receiving homologous blood transfusions and having had wound drainage would have benefited from a re-transfusion system, because the amount of drained fluid within the first $6 \mathrm{~h}$ did not reach the minimal volume threshold of $250 \mathrm{ml}$ given by the provider. Safety concerns about unwashed, filtered shed blood causing febrile reaction, hypotension, confusion, cardiac or pulmonary compromise, coagulopathy or even death due to complement split products and pro-inflammatory cytokines [19] are the reasons for these $6 \mathrm{~h}$ and $250 \mathrm{ml} \mathrm{limits} \mathrm{[18].}$

According to these limits only three patients $(7 \%)$ get drainage fluid re-transfused. This is far away from the re-transfusion rate of $76 \%$ reported by Smith et al. [11]. In his patient collective, a transgluteal hip approach was used. However, other investigators did not see advantages of postoperative re-transfusion-systems in primary THR $[9,10]$, too. Additionally, all three patients benefiting from re-transfusion in the present study were far away from being in need for blood transfusions, when their postoperative $\mathrm{Hb}$ values were analyzed. We therefore assume that the main factor leading to homologous blood transfusions in our collective of patient must have been intraoperative bleeding or diffuse bleeding not accessible by the drain and not the amount of postoperatively drained fluid. We therefore conclude that, for our current practice of primary THR, the possibility of giving drained blood back to the patient does not reduce the risk of homologous blood transfusion and is not an argument supporting the use of drains.

To omit drains had two opposite effects in our patients: (1) more thigh swelling accompanied with a tendency of higher volumes of hematoma and higher pain scores during the first day and (2) earlier dry operation sites resulting in simplified wound care and shorter hospital stay. It is a weakness of the present study that sample size did not allow higher pain scores and higher hematoma volumes in group A to reach significance level. However, it corresponds well with our anecdotic impression and with other studies showing smaller hematomas when closed suction drains are used [16, 20]. However, in terms of clinical outcome at 3 months and the incidence of heterotopic ossifications, this higher hematoma volume did not have a measurable impact. Prolonged oozing from drainage holes have been reported by other investigators $[1,6,16]$, too, and seem to be a main disadvantage of drains.

In conclusion, there was no obvious advantage for a retransfusion system in our series. Earlier dry operation sites resulting in simplified wound care and shorter hospital stay was an advantage of omitting drains and must be weighed against more thigh swelling and a tendency of higher pain scores during the first operative days. For our practice, we decided to omit drains in simple primary non-cemented THR using the direct anterior approach.

Conflict of interest The authors declare that they don't have any conflict of interest.

\section{References}

1. Cobb JP (1990) Why use drains? J Bone Joint Surg Br 72(6):993-995

2. Waugh TR, Stinchfield FE (1961) Suction drainage of orthopaedic wounds. J Bone Joint Surg Am 43-A:939-946

3. Magee C, Rodeheaver GT, Golden GT, Fox J, Edgerton MT, Edlich RF (1976) Potentiation of wound infection by surgical drains. Am J Surg 131(5):547-549

4. Overgaard S, Thomsen NO, Kulinski B, Mossing NB (1993) Closed suction drainage after hip arthroplasty. Prospective study of bacterial contamination in 81 cases. Acta Orthop Scand 64(4):417-420

5. Sorensen AI, Sorensen TS (1991) Bacterial growth on suction drain tips. Prospective study of 489 clean orthopedic operations. Acta Orthop Scand 62(5):451-454

6. Mengal B, Aebi J, Rodriguez A, Lemaire R (2001) A prospective randomized study of wound drainage versus non-drainage in 
primary total hip or knee arthroplasty. Rev Chir Orthop Reparatrice Appar Mot 87(1):29-39

7. Grosvenor D, Goyal V, Goodman S (2000) Efficacy of postoperative blood salvage following total hip arthroplasty in patients with and without deposited autologous units. J Bone Joint Surg Am 82-A(7):951-954

8. Han CD, Shin DE (1997) Postoperative blood salvage and reinfusion after total joint arthroplasty. J Arthroplasty 12(5):511-516

9. Mauerhan DR, Nussman D, Mokris JG, Beaver WB (1993) Effect of postoperative reinfusion systems on hemoglobin levels in primary total hip and total knee arthroplasties. A prospective randomized study. J Arthroplasty 8(5):523-527

10. Rollo VJ, Hozack WJ, Rothman RH, Chao W, Eng KO (1995) Prospective randomized evaluation of blood salvage techniques for primary total hip arthroplasty. J Arthroplasty 10(4):532-539

11. Smith LK, Williams DH, Langkamer VG (2007) Post-operative blood salvage with autologous retransfusion in primary total hip replacement. J Bone Joint Surg Br 89(8):1092-1097

12. Strumper D, Weber EW, Gielen-Wijffels S, Van Drumpt R, Bulstra S, Slappendel R, Durieux ME, Marcus MA (2004) Clinical efficacy of postoperative autologous transfusion of filtered shed blood in hip and knee arthroplasty. Transfusion 44(11):1567-1571

13. Charrois O, Kahwaji A, Gagnaire AL, Courpied JP (2005) Variables influencing bleeding during total hip arthroplasty. Rev Chir Orthop Reparatrice Appar Mot 91(2):132-136

14. Brooker AF, Bowerman JW, Robinson RA, Riley LH (1973) Ectopic ossification following total hip replacement. Incidence and a method of classification. $\mathrm{J}$ Bone Joint Surg Am 55(8):1629-1632

15. Juelsgaard P, Larsen UT, Sorensen JV, Madsen F, Soballe K (2001) Hypotensive epidural anesthesia in total knee replacement without tourniquet: reduced blood loss and transfusion. Reg Anesth Pain Med 26(2):105-110

16. Dora C, von Campe A, Mengiardi B, Koch P, Vienne P (2007) Simplified wound care and earlier wound recovery without closed suction drainage in elective total hip arthroplasty. A prospective randomized trial in 100 operations. Arch Orthop Trauma Surg 127(10):919-923

17. Healy JC, Frankforter SA, Graves BK, Reddy RL, Beck JR (1994) Preoperative autologous blood donation in total-hip arthroplasty. A cost-effectiveness analysis. Arch Pathol Lab Med 118(4):465-470

18. Henry DA, Carless PA, Moxey AJ, O'Connell D, Forgie MA, Wells PS, Fergusson D (2002) Pre-operative autologous donation for minimising perioperative allogeneic blood transfusion. Cochrane Database Syst Rev 2:CD003602

19. Andersson I, Tylman M, Bengtson JP, Bengtsson A (2001) Complement split products and pro-inflammatory cytokines in salvaged blood after hip and knee arthroplasty. Can J Anaesth 48(3):251-255

20. Kim YH, Cho SH, Kim RS (1998) Drainage versus nondrainage in simultaneous bilateral total hip arthroplasties. J Arthroplasty 13(2):156-161 